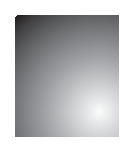

\title{
A Visão Baseada em Recursos da Inteligência Competitiva
}

\author{
The Resource-Based View of Competitive Intelligence
}

\section{Paulo Henrique de Oliveira}

Professor do Instituto Federal de Minas Gerais - Belo Horizonte-MG, Brasil. E-mail: peagad@yahoo.com.br

\section{Carlos Alberto Gonçalves}

Professor na Faculdade de Ciências Econômica FACE/UFMG - Belo Horizonte - MG, Brasil. E-mail: carlos@face.ufmg.br

Edmar Aderson Mendes de Paula

Professor da Faculdade Pitágoras do departamento de Engenharia Mecânica - Betim - MG. Brasil. E-mail: EDMARP@pitagoras.com.br

\section{Resumo}

Neste artigo será analisada a importância da Inteligência Competitiva (IC) como uma capacidade estratégica para as organizações contemporâneas, especialmente para aquelas instaladas em ambientes de intensa e de dinâmica competição. A discussão acontece no contexto da Visão Baseada em Recursos, uma das mais importantes correntes teóricas do campo da estratégica que busca explicar o fenômeno da vantagem competitiva a partir do controle de recursos e capacidades diferenciados pelas organizações. Como suposição inicial acredita-se que o valor estratégico da IC está concentrado, principalmente, no conhecimento tácito dos seus profissionais e nos relacionamentos construídos ao longo do tempo (path dependence) com seus pares e tomadores de decisões estratégicas de suas respectivas organizações, uma vez que eles não podem ser imitados ou desenvolvidos rapidamente pelos concorrentes, conforme sugerem os estudos de autores como Wernerfelt (1984), Nonaka e Takeuchi (1995), Barney (1986, 1991, 2001), Dierickx e Cool (1989), Mahoney e Pandian (1992), Amit e Schoemaker (1993) e Grant $(1991,1996)$.

Palavras-chave: Inteligência Competitiva. Visão Baseada em Recursos. Vantagem Competitiva. Pesquisa Teórica.

\section{Abstract}

This paper analyzes the importance of Competitive Intelligence $(\mathrm{CI})$ as a strategic capability for contemporary organizations, especially those installed in environments characterized by an intense and dynamic competition. The discussion takes place in the context of the Resource-Based View, one of the most important theoretical approaches in the field of strategic attempt to explain the phenomenon of competitive advantage. In conclusion, it is believed that the strategic value of IC is concentrated mainly in the tacit knowledge of its professionals and the relationships built over time (path dependence) with their peers and strategic decision makers in the yours organizations, since that they can not be imitated by competitors or developed rapidly, as suggested by the studies of Wernerfelt (1984), Nonaka and Takeuchi (1995), Barney (1986, 1991, 2001), Dierickx and Cool (1989), Mahoney and Pandian (1992), Amit and Schoemaker (1993) and Grant (1991, 1996).

Key words: Competitive Intelligence. Resource-Based View. Competitive Advantage. Theoretical Study. 


\section{INTRODUÇÃO}

Nesses tempos caracterizados por uma intensa $e$ dinâmica competição, em que vantagens competitivas tendem a ser rapidamente imitadas ou superadas pelos concorrentes (D'AVENI et al. 2010; SIRMON, et al. 2010), a única certeza é a de que os estrategistas do terceiro milênio precisarão contar com informações cada vez mais confiáveis, precisas e instantâneas sobre tudo o que está acontecendo à sua volta, especialmente informações de alto valor agregado que os permitam identificar e antecipar, rapidamente, as ameaças e as oportunidades impostas por seus ambientes de negócios em constante transformação, além de um melhor conhecimento dos fatores internos das suas organizações (forças e fraquezas) que possam ter algum impacto sobre o processo estratégico e, consequentemente, sobre o desempenho competitivo delas.

Por causa do crescimento e da modernização da competição, percebidos em praticamente todos os setores econômicos mundiais (CHEN et al., 2010; ANG, 2008; ANTIA; HERSFORD, 2007; OLIVEIRA et al., 2007; PIRTTIMÄKI, 2007; GORDON, 2004), muitos modelos tradicionais de gestão se demonstraram incapazes de conduzirem as organizações à conquista de vantagens competitivas sustentáveis e desempenhos financeiros superiores em seus respectivos mercados. Em decorrência, observa-se que em ambientes competitivos caracterizados como incertos e turbulentos fatores como flexibilidade estrutural, inovação contínua, rapidez e eficácia decisórias podem ser determinantes para que as organizações sobrevivam e prosperem em seus respectivos setores industriais ao longo do tempo.

A mudança na natureza da competição, ocorrida neste início de século XXI em decorrência da transição de uma economia industrial para uma nova ordem econômica mundial, em que informação e conhecimento assumem o status de recursos valiosos, estratégicos e multiplicáveis, uma vez que não se exaurem quando são consumidos no processo produtivo, ao contrário, se expandem quando são compartilhados entre as pessoas, tem proporcionado desafios crescentes para os tomadores de decisões estratégicas, e dentre os principais estão a crescente entrada de novos competidores no mercado em decorrência da globalização, as rápidas inovações tecnológicas (ex: setores automobilísticos e da tecnologia da informação) e as mudanças no comportamento de compra dos consumidores, que estão cada vez mais exigentes. (D'AVENI et al. 2010; SIRMON, et al. 2010; CHEN et al. 2010)

Com um cenário cada vez mais desafiador, a Inteligência Competitiva (IC) tem emergido com a promessa de ajudar os tomadores de decisões estratégicas a reduzirem os riscos de falhas das estratégias competitivas a serem formuladas e implementadas, especialmente pela disponibilização oportuna e rápida de produtos de inteligência acionáveis que os ajudem a melhor se condicionarem frente às possíveis ameaças competitivas como, também, na descoberta de novas oportunidades de negócios que permitam às suas organizações se manterem continuamente à frente dos concorrentes, especialmente na conquista de maiores participações de mercado ou market-share.

É nesse contexto que a presente pesquisa se insere. Buscando-se inspirações filosóficas e epistemológicas em uma das mais importantes correntes teóricas desenvolvidas nesses últimos anos no campo da estratégia de negócios - a Visão Baseada em Recursos (Resource-Based View - RBV, no inglês) - este estudo busca, então, respostas para as seguintes questões: a IC pode ser considerada uma capacidade estratégica para as organizações na atualidade? Se sim, de que forma isso pode acontecer e quais recursos tangíveis e intangíveis da respectiva capacidade podem ser determinantes para o alcance da respectiva condição?

Assim, espera-se contribuir para o desenvolvimento de um novo olhar ou perspectiva de abordagem do tema da IC, especialmente na identificação dos recursos humanos, tecnológicos, materiais e informacionais utilizados em cada uma de suas etapas e que são estratégicos para o seu desempenho otimizado, mais precisamente, para a eficiência com que eles são convertidos em produtos de inteligência acionáveis. Para os gestores organizações a presente pesquisa pode ser um marco orientador para a condução de suas políticas e estratégias de alocação dos respectivos recursos em suas capacidades diferenciadas, como é o caso da IC em questão.

Estruturalmente esta pesquisa está organizada da seguinte forma: na primeira parte, da qual faz parte esta introdução, contextualiza-se os temas e apresenta o problema de pesquisa, operacionalizado por duas questões principais; em seguida, na segunda parte, são apresentadas características principais da Visão 
Baseada em Recursos, doravante denominada RBV; já na terceira parte discorre-se sobre a IC na dimensão processo, com especial destaque para os recursos e capacidades que são importantes para a sua consecução; por fim, na quarta parte, conclui-se o estudo e algumas sugestões de pesquisas são apresentadas.

\section{Visão Baseada em Recursos}

Na literatura da estratégia, um conjunto de teorias e modelos tem sido desenvolvido nessas últimas décadas para explicar o porquê que determinadas organizações conseguem conquistar e sustentar vantagens competitivas por longos períodos de tempo e outras não, mesmo quando todas elas instaladas dentro de um mesmo mercado ou setor industrial (WERNERFELT, 1984; BARNEY, 1986, 1991; BARNEY; HESTERLY, 2007). E dentre as principais estão as da Organização Industrial (OI), de Processos de Mercado (PM), da Visão Baseada em Recursos (VBR ou RBV, no inglês) e das Capacidades Dinâmicas (CD).

Resumidamente, as duas primeiras (OI e PM) foram fortemente influenciadas pelo pensamento econômico, especialmente pelas ideias iniciais de economistas como Mason (1939), Bain (1959), Schumpeter (1934) e Hayek (1937, 1945). Para os autores da OI, por exemplo, o comportamento e o desempenho das organizações (veja o modelo Estrutura-Conduta-Desempenho) eram dependentes da estrutura da indústria e dos mercados em que elas estavam inseridas. $\mathrm{E}$, como consequência, as organizações eram vistas como variáveis dependentes em relação às condições competitivas existentes em suas respectivas indústrias e mercados, cabendo aos seus decisores estratégicos o simples papel de adaptação das suas organizações aos desafios impostos por seus ambientes de negócios. Assim, a estrutura do mercado e da indústria determina a conduta (estratégia) e, esta, o desempenho organizacional. (PORTER, 1981)

Essa condição é retratada nos estudos realizados por Michael Porter no início da década de 1980 ao considerarem aspectos como estratégia e vantagem competitivas e as técnicas para análise da indústria e dos competidores. E em seu modelo conhecido na literatura como "Cinco Forças" (poder de barganha dos fornecedores e dos compradores, ameaças de novos entrantes e de produtos substitutos e o nível de rivalidade existente entre os concorrentes) o autor reconheceu que a lucratividade de cada organização depende mais da influência conjunta das respectivas forças do que das capacidades e recursos estratégicos controlados por ela.

Em decorrência, restava aos estrategistas um papel secundário frente ao impacto das respectivas forças sobre as suas organizações, especialmente na escolha do posicionamento estratégico mais adequado em seus respectivos mercados, que poderia ser obtido em decorrência de estratégias baseadas na diferenciação dos produtos e serviços disponibilizados, de liderança em custos ou de foco (ambas). Essas estratégias ficaram conhecidas na literatura como estratégias genéricas. (PORTER, 1980, 1985)

A outra corrente teórica, conhecida como Processos de Mercado, foi idealizada principalmente por economistas como Schumpeter (1934) e Hayek (1945). Para o respectivo autor, a natureza dinâmica da competição e dos mercados é a força propulsora do processo estratégico, especialmente pelo incentivo a um comportamento inovador ou empreendedor dos empresários na busca por lucros extraordinários ou acima da média. Esse comportamento "oportunista" dos respectivos agentes organizacionais conduz ao que Schumpeter (1934) chamou de "destruição criativa", ou seja, processo de ruptura das condições vigentes (status quo) para uma nova condição, muitas vezes desconhecidas e altamente arriscadas, mas que normalmente tende a valer a pena pelos elevados retornos que o respectivo comportamento proporciona.

Entretanto, com a limitada ênfase dispensada pelos autores das respectivas correntes teóricas para os fatores endógenos às organizações na análise dos fenômenos da vantagem competitiva e do desempenho superior, especialmente para os recursos e capacidades diferenciados controlados pelas mesmas que pudessem ser utilizados no processo estratégico, novas propostas emergiram na literatura da estratégia com o propósito de suprir a respectiva lacuna. E dentre as principais delas estão a Visão Baseada em Recursos e a das Capacidades Dinâmicas, inicialmente propostas por autores como Wernerfelt (1984), Barney (1986, 1991, 1995, 2001, 2002), Dierickx e Cool (1989), Mahoney e Pandian (1992), Amit e Schoemaker (1993), Peteraf (1993), Spender (1996) e Grant (1991, 1996), 
dentre outros, não se esquecendo das contribuições seminais de Penrose (1959) sobre o crescimento das organizações.

Precisamente no contexto da Visão Baseada em Recursos, vantagens competitivas conquistadas por determinadas organizações poderiam ser explicadas mais pelo lado do controle de recursos e capacidades diferenciados do que da estrutura da indústria, da competição e dos mercados, conforme as ideias dos autores da OI e da PM. Nas palavras de Barney e Hesterly (2007, p. 67), recursos são definidos como "[...] ativos tangíveis e intangíveis que a empresa controla e que podem ser usados para criar e implementar estratégias [...]" e por capacidades "[...] um subconjunto de recursos de uma empresa [...] que permitem à empresa aproveitar por completo outros recursos que controla".

Barney e Hesterly (2007, p. 67) ainda ressaltam que "[...] as capacidades, sozinhas, não permitem que uma empresa crie e implemente suas estratégias, mas permitem que utilize outros recursos para criar e implementar tais estratégias". E dentre as principais categorias de recursos e capacidades apresentadas pelos autores estão os recursos financeiros, físicos, individuais e organizacionais, conforme se observa no Quadro 1.

\begin{tabular}{cl}
$\begin{array}{c}\text { RECURSOS E CAPA- } \\
\text { CIDADES }\end{array}$ & \multicolumn{1}{c}{ ExEMPLOS } \\
\hline Financeiros & $\begin{array}{l}\text { Dinheiro de qualquer fonte (empreendedores, } \\
\text { acionistas, credores, bancos); lucros retidos. }\end{array}$ \\
\hline Físicos & $\begin{array}{l}\text { Tecnologia física - planta e equipamentos; } \\
\text { localização geográfica; acesso à matéria-prima. }\end{array}$ \\
Individuais & $\begin{array}{l}\text { Treinamento; experiência; julgamento; } \\
\text { inteligência; relacionamentos; visão individual } \\
\text { dos gerentes e dos funcionários. }\end{array}$ \\
Organizacionais & $\begin{array}{l}\text { Estrutura formal; sistemas formais e informais } \\
\text { de planejamento, controle e coordenação; } \\
\text { cultura e reputação; relações informais entre } \\
\text { grupos da empresa e demais stakeholders (fora } \\
\text { da empresa). }\end{array}$ \\
\hline
\end{tabular}

Quadro 1: Recursos e capacidades organizacionais no contexto da RBV

Fonte: Adaptado de Barney (1991) e Barney e Hesterly (2007)

Os autores da RBV ainda destacam algumas suposições críticas que precisam ser atendidas para que a respectiva corrente teórica seja capaz de explicar adequadamente a conquista $e$ a sustentação de vantagens competitivas por determinadas organizações que operam dentro de um mesmo setor industrial. A primeira delas se sustenta na ideia de que diferentes organizações controlam conjuntos diferentes de recursos e capacidades. Em outras palavras, supõe-se a existência de uma heterogeneidade de recursos entre as respectivas organizações.

Conforme destacam Barney e Hesterly (2007, p. 65), "[...] heterogeneidade de recursos significa que, para determinado ramo de atividade, algumas empresas podem ser mais competentes em realizar essa atividade do que outras". Os autores exemplificam a respectiva suposição com os casos da Toyota e da Apple. Para eles, a Toyota continua mais competente do que a General Motors em termos de manufatura e, no design, a Apple tem obtido melhores resultados do que a IBM, apesar de elas terem obtido algum progresso em lidar com as suas desvantagens.

Já em relação à segunda suposição, a da imobilidade de recursos, ela se baseia na ideia de que as diferenças de recursos e capacidades podem durar muito tempo, isso porque "[...] pode ser muito custoso para as empresas sem certos recursos e capacidades desenvolvê-los ou adquiri-los" (BARNEY; HESTERLY, 2007, p. 65). Assim, consideradas juntas, as respectivas suposições ajudam os pesquisadores a explicarem por que determinadas organizações superam outras, mesmo quando todas elas estejam competindo dentro de um mesmo mercado. Em outras palavras

\section{[...] se uma empresa possui recursos e capa- cidades valiosos que poucas outras empresas possuem, e se essas outras empresas consideram muito custoso imitar esses recursos e capaci- dades, a empresa que possui esses ativos tan- giveis e intangíveis pode obter uma vantagem competitiva sustentável. (BARNEY; HESTERLY, 2007, p. 65-66)}

E para que um recurso ou capacidade possa ser considerado como potencial fonte de vantagem competitiva, eles devem atender a quatro critérios ou condições específicas do modelo VRIO inicialmente proposto por Barney (1991), quais sejam: (a) devem ser valiosos, ou seja, eles devem permitir que os estrategistas explorem oportunidades de negócios e/ou neutralizem possíveis ameaças; (b) devem ser raros, ou seja, eles só podem ser controlados apenas por um pequeno número de organizações concorrentes; (c) devem ser inimitáveis, ou seja, as organizações sem os 
recursos e as respectivas capacidades enfrentam uma desvantagem de custo para obtê-los e, finalmente; (d) devem ser organizáveis, ou seja, as políticas e os procedimentos da organização em questão estão estruturados para dar suporte à exploração dos respectivos recursos e capacidades valiosos, raros e custosos de serem imitados. (BARNEY, 1991)

\section{O Valor Estratégico da Inteligência COMPETITIVA}

Inteligência Competitiva (IC) tem se tornado um campo promissor de pesquisa na atualidade, especialmente pela sua importância para o processo estratégico de organizações que enfrentam ambientes competitivos, caracterizados por uma intensa e dinâmica competição, e são também chamados por D'Aveni (1995) de ambientes hipercompetitivos. E nesses tipos de ambientes, vantagens competitivas tendem a ser rapidamente imitadas ou superadas pelos concorrentes, uma vez que muitos competidores estão a todo o instante desenvolvendo novos produtos, serviços e tecnologias. (SIRMON et al. 2010)

Como a maioria das técnicas e metodologias empregadas no campo da estratégia, a IC tem uma de suas raízes históricas no ambiente militar, especialmente nos ensinamentos que podem ser abstraído das guerras. $\mathrm{E}$ uma das principais fontes apontadas pelos autores está nos ensinamentos de Sun Tzu sobre a Arte da Guerra, especialmente na seguinte passagem:

[...] se você conhece o inimigo e conhece a si mesmo, não precisa temer o resultado de cem batalhas. Se você se conhece, mas não conhece o inimigo, para cada vitória ganha sofrerá também uma derrota. Se você não conhece nem o inimigo nem a si mesmo, perderá todas as batalhas. [...] (MORESI, 2001, p. 43)

O respectivo trecho destaca, mesmo que indiretamente ou subjetivamente, a importância da IC ao chamar a atenção para a necessidade do monitoramento dos fatores internos (forças e fraquezas) e externos às organizações (ameaças e oportunidades) que possam influenciar o processo estratégico e, consequentemente, o desempenho delas nos mercados (campos de batalha) em que estão inseridas, e este processo de acompanhamento do ambiente competitivo tem sido uma incumbência atual das unidades de IC, especialmente nas grandes organizações. (PORTER, 1980; FULD, 1995; KAHANER, 1996; HERRING, 2002; BERGERON; HILLER, 2002; McGONAGLE; VELLA, 2004; LIEBOWITZ, 2006; NEWBERT, 2007)

Outras referências históricas também têm sido apontadas pelos estudiosos da IC (ex. PRESCOTT, 1999), com especial destaque para as políticas de segurança nacional, desenvolvidas pelos governos nos períodos da Segunda Guerra Mundial e da Guerra Fria, e para as contribuições de Michael Porter no início da década de 1980 ao trazer para o centro da discussão a necessidade de um acompanhamento sistemático e contínuo dos movimentos realizados ou intencionados pelos competidores em suas respectivas indústrias. Especialmente neste último caso, a IC ganhou destaque entre os pesquisadores da estratégia, o que pode ser comprovado pelo grande número de pesquisas acadêmicas realizadas desde então.

$\mathrm{Na}$ literatura da IC, ela tem sido considerada pela grande parte dos autores interessados no respectivo tema como um processo composto pelas etapas de planejamento, coleta, análise e disseminação dos produtos de inteligência para os usuários, mais precisamente, para os tomadores de decisões estratégicas. Kahaner (1996), por exemplo, tem definido a IC como um programa sistemático de coleta e análise das informações sobre as atividades dos competidores e das tendências gerais dos negócios para a consecução dos objetivos empresariais. Miller (2002, p. 13) complementa defendendo que a "[...] inteligência é mais do que ler artigos em jornais; ela está relacionada com o desenvolvimento de insights únicos e de questões relevantes sobre o ambiente de negócios das empresas".

Na perspectiva de West (2001, p. 12), a IC é "[...] o processo pelo qual as empresas informam a elas mesmas sobre todos os aspectos relacionados com as atividades e desempenho dos rivais". Ainda nas palavras do respectivo autor (WEST, 2001, p. 12), a IC é "[...] um essencial ingrediente não apenas para o planejamento das campanhas de marketing, mas, também, para os programas de produção, recursos humanos, finanças e todas as demais atividades corporativas que os competidores podem influenciar direta ou indiretamente". 
Tarapanoff (2001, p. 45), uma importante referência nacional no assunto, entende a IC como "[...] um processo sistemático que transforma pedaços esparsos de dados em conhecimento estratégico". Mais precisamente,

[...] é informação sobre produtos específicos e tecnologias [...] é monitoramento de informação externa que afeta o mercado da organização, como, por exemplo, informação econômica, regulatória, política e demográfica. (TARAPANOFF, 2001, p. 45)

Ainda nas palavras da respectiva autora (TARAPANOFF, 2001, p. 45), a IC envolve a "[...] habilidade de desenvolver o entendimento das estratégias e da forma de agir de seus competidores-chave [...]" e um dos seus principais fatores críticos de sucesso "[...] é o de desenvolver a percepção da provável reação que um novo desenvolvimento industrial ou uma iniciativa de sua organização pode causar em seus competidores".

Em relação ao valor da IC para o processo estratégico, Tarapanoff (2001) ainda salienta que o acompanhamento sistemático e contínuo dos competidores, dos consumidores, dos fornecedores e de outras forças industriais deve integrar o processo de gestão estratégica das empresas, uma vez que o monitoramento contínuo do ambiente competitivo e de negócios ajuda os gestores estratégicos a prevenirem surpresas, como também, a implementarem estratégias competitivas mais eficazes e a tempo hábil. (TARAPANOFF, 2001)

Quando se analisa a primeira etapa do processo de IC, o planejamento das suas atividades, duas questões precisam ser eficazmente, respondidas pela equipe de IC, ou seja: quais são as necessidades de inteligência da organização e quais são os seus respectivos usuários. Para Starec et al. (2005), a respectiva etapa é a mais importante do respectivo processo e algumas perguntas podem direcionar o trabalho dos profissionais de inteligência, como, por exemplo: (a) quais decisões precisam ser tomadas? (b) O quê os decisores precisam saber? (c) O quê os decisores já sabem? Por que os decisores precisam saber de um determinado evento e em que momento? (d) O quê os decisores farão com a inteligência disponibilizada? (e) quanto custará obter o respectivo conhecimento competitivo e (f) qual é o custo de não obtê-la? Nas palavras dos respectivos autores (STAREC et al., 2005, p. 112) "[...] essas questões, embora pareçam simples e óbvias, despertam no entrevistado a importância do foco da resposta".

Já em relação à segunda etapa do processo de IC, a coleta e tratamento dos dados e das informações, os profissionais de inteligência direcionam os seus esforços na identificação das fontes de informações mais relevantes e confiáveis, que podem ser provenientes tanto dos ambientes interno quanto externo das organizações. E uma classificação bastante utilizada pelos pesquisadores tem sido no tocante à natureza delas, que podem ser pessoais (ou primárias) ou impessoais (secundárias) (CHOO, 1995). O Quadro 2 resume algumas das principais fontes de informações que podem ser acessadas pelos profissionais de inteligência nesta etapa do processo.

\begin{tabular}{ll}
\multicolumn{1}{c}{ FontEs INTERNAS } & \multicolumn{1}{c|}{ Fontes ExtERNAS } \\
\hline Funcionários da organização & $\begin{array}{l}\text { Agências de Publicidade } \\
\text { da organização }\end{array}$ \\
\hline Engenharia & Bancos \\
\hline Finanças & Consultores \\
\hline Recursos Humanos & Clientes \\
\hline Centros de Informação & Distribuidores \\
\hline Produção & Imprensa Geral ou Setorial \\
\hline Marketing & Fabricantes de Equipamentos \\
Suprimentos & Analistas Financeiros \\
\hline Relações Públicas & Governo \\
\hline Pesquisa e Desenvolvimento & Sindicatos \\
\hline Vendas & Advogados \\
\hline & Especialistas em Patentes \\
& Ex-funcionários da organização \\
\hline & Fornecedores \\
\hline & Associações Setoriais \\
\hline
\end{tabular}

Quadro 2: Fontes de informação para a geração de inteligência competitiva

Fonte: Adaptado de Gordon (2004) e de Barbosa (2006)

De posse dos dados e das informações, os profissionais de inteligência direcionam os seus esforços intelectuais para a sua análise na tentativa de encontrar algum padrão ou insight que seja útil para a tomada de decisão estratégica. Nessa etapa do processo de IC é comum os respectivos analistas utilizarem técnicas e 
métodos avançados de análise, como, por exemplo, o modelo das Cinco Forças de Porter, o método dos Fatores Críticos de Sucesso, a Análise de Cenários, estudos sobre o Perfil dos Concorrentes, a técnica de Benchmarking, e a análise SWOT. (TARAPANOFF, 2001)

Conforme destacam Starec et al. (2005), as principais dificuldades encontradas nesta etapa se relacionam com o treinamento da equipe de IC em metodologias de análise, uma vez que ele demanda tempo e persistência por parte dos analistas e a falta de sensibilização quanto à importância da tarefa por parte dos demais colaboradores, que normalmente não valorizam adequadamente a respectiva atividade.

Na última etapa do respectivo processo, os produtos de inteligência devem ser disponibilizados para os respectivos usuários em formatos adequados e coerentes com as necessidades deles. E alguns pontos precisam ser observados ou identificados previamente, tais como: (a) os mecanismos de distribuição dos produtos de inteligência mais adequados, conforme acordado previamente com os tomadores de decisões estratégicas (ex: relatórios customizados, apresentações, análises setoriais, boletins, dentre outros); (b) a definição da linguagem, forma e facilidade de acesso aos produtos de inteligência (disseminação focada - para os usuários e geral - para todos na organização); (c) a definição da frequência de envio dos respectivos produtos de inteligência e (d) a credibilidade da análise (STAREC et al. 2005). A Figura 1 ilustra o respectivo processo de IC e a sua interação com o processo estratégico.

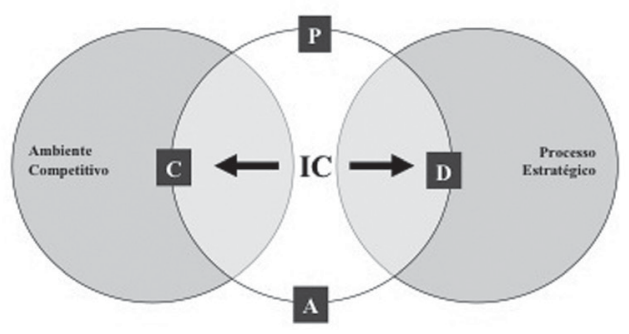

Figura 1: A perspectiva da IC como uma capacidade intermediadora entre ambiente competitivo e processo estratégico

Fonte: Elaborada pelos autores deste artigo

De acordo com a Figura 1, observa-se que a IC tem um papel fundamental como variável inter- mediadora entre ambiente competitivo e processo estratégico, uma vez que ela monitora os eventos de interesse do ambiente competitivo da organização por meio da coleta de dados e informações relevantes para posterior transformação e disponibilização, na forma de inteligência acionável, para os tomadores de decisões estratégicas. (WEST, 2001; MILLER, 2002; BERNHARDT, 2003; LIEBOWITZ, 2006)

Assim, uma possível hipótese que emerge desta dupla orientação (veja as setas na Figura 1), e ainda não efetivamente explorada pelos pesquisadores contemporâneos, é se as organizações que possuem estruturas eficientes e eficazes de IC conquistam e sustentam vantagens competitivas por longos períodos de tempo em seus respectivos mercados consumidores em decorrência da possível redução dos riscos envolvidos nos processos de formulação e implementação de estratégias competitivas. Em outras palavras, qual é a ligação dos esforços de inteligência empreendidos por uma organização e o seu desempenho? Quais recursos e capacidades são determinantes para a eficiência e eficácia dos esforços de IC? Como se pode medir o valor estratégico dos produtos de inteligência gerados no processo de IC? A resposta das respectivas questões talvez seja um dos principais desafios dos pesquisadores contemporâneos.

Por exemplo, em um estudo de caso realizado em uma organização multinacional com aproximadamente 100 mil funcionários e operando em 110 países, Maguire et al. (2009) analisaram o modo de como ela gerencia os esforços de IC para o alcance de maior competitividade e vantagem estratégica. As conclusões do respectivo estudo, apesar de vagos, destacam a importância das organizações contemporâneas de investirem nos aspectos humanos relacionados com a gestão da inteligência organizacional.

Zangoueinezhad e Moshabaki (2009), por sua vez, em uma survey realizada com 200 organizações de grande porte exploraram o papel do capital estrutural, chamado por eles de inteligência, na obtenção, produção e transmissão dos produtos de inteligência competitiva para aumentar a vantagem competitiva das respectivas organizações. Os resultados encontrados demonstram que existe uma relação positiva e significativa entre IC e conquista de vantagem competitiva.

Investigando empiricamente como a atitude empreendedora $e$ as crenças normativas influenciam 
o comportamento informacional dos gestores em termos de monitoramento (inteligência competitiva) e a interpretação deles em relação às forças e fraquezas organizacionais dentro de suas arenas competitivas, Qiu (2008), por meio da modelagem de equações estruturais, coletou dados de 309 gestores de organizações norte-americanas, observou que a atitude empreendedora e a orientação para o mercado têm um impacto significativo pela procura dos gerentes por produtos de inteligência, e que eles os ajudam a melhor interpretar a natureza da vantagem competitiva conquistada por suas organizações.

Finalmente, em uma pesquisa realizada por Pirttimaki (2007) com 41 gerentes de organizações instaladas em 17 países, o respectivo autor, ao comparar as práticas de IC das respectivas organizações com as da Finlândia, observou que elas normalmente são utilizadas não apenas para neutralizar as ameaças competitivas, mas para a descoberta de novas oportunidades de negócios, tendências e sinais fracos enviados pelos ambientes de negócios. Para o respectivo autor, a grande parte das organizações possui sistemas de informação para dar suporte às atividades de IC das respectivas organizações.

A partir desta pequena amostra de pesquisas realizadas sobre a IC, observa-se que ela tem ocupado a agenda de muitos pesquisadores ao redor do mundo nesses últimos anos, talvez em decorrência do aumento dos desafios proporcionados pelo acirramento da competição percebido em praticamente todos os setores econômicos mundiais e pela sua importante contribuição para a eficácia do processo estratégico. Muitas questões ainda precisam ser respondidas, especialmente em relação aos fatores organizacionais (ex. cultura e estrutura organizacionais, organização formal e informal, sistema de recompensas, etc.) e recursos internos (informacionais, tecnológicos e humanos) que são determinantes para que o processo de IC aconteça da maneira eficiente e eficaz.

\section{Considerações Finais e uma Agenda de Pesquisa}

Parece não haver mais dúvidas significativas de que a IC é um tema em expansão e consolidação na literatura da estratégia de negócios e em disciplinas correlatas, como é o caso da gestão da informação e do conhecimento. Especialmente nesses últimos anos, um grande número de pesquisadores tem se interessado, cada vez mais, pelos esforços de inteligência empreendidos por determinadas organizações na tentativa de conquistarem melhores condições competitivas e, consequentemente, de desempenhos superiores ou acima da média em seus respectivos mercados consumidores.

Buscando-se contribuir para a evolução da base de conhecimentos existente sobre o respectivo assunto, especialmente por sua análise no contexto de uma das mais importantes correntes teóricas desenvolvidas nesses últimos anos para uma melhor compreensão do fenômeno da vantagem competitiva - a Visão Baseada em Recursos - o presente estudo se concentrou nos aspectos centrais que podem contribuir para que a IC possa ser considerada como uma capacidade estratégica para as organizações contemporâneas.

A partir da pesquisa teórica realizada, observa-se que a IC tem um papel de fundamental importância para o desempenho superior das organizações, especialmente para àquelas instaladas em ambientes hipercompetitivos, mesmo que indiretamente. Como o objetivo central do processo estratégico defendido pelos autores da estratégia tem sido o de ajustar, eficazmente e rapidamente, as organizações aos desafios (ameaças e oportunidades) impostos por seus ambientes de negócios (CHANDLER, 1962; ANSOFF, 1965, 1993; PORTER, 1980, 1985), a IC assume papel de destaque, uma vez que ela tem exercido um importante papel de ligação entre o comportamento estratégico adotado pelas organizações e os seus ambientes de negócios (ver Figura 1), especialmente por que os seus profissionais transformam os dados e as informações coletados deles em produtos de inteligência acionáveis para os decisores estratégicos. (FULD, 1995; KAHANER, 1996; TYSON, 1998; HERRING, 2002; BERNHARDT, 2003)

Especificamente em relação ao valor estratégico da IC para as organizações neste início de século XXI, a estrutura proposta por Barney (1991) e Barney e Hesterly (2007) pode ser determinante para esse fim. Assim, para ser considerada como uma capacidade estratégica, a IC deve ser valiosa para a organização (ajudá-la na neutralização de ameaças e na descoberta de novas oportunidades de negócios), rara (poucas organizações possuem estruturas eficientes de IC), 
inimitável (não podem ser copiadas ou desenvolvidas facilmente pelas demais organizações concorrentes) e, por fim, organizáveis, ou seja, as organizações devem ser capazes de gerenciar as suas estruturas de inteligência de maneira eficiente e eficaz.

Esses parecem ser os desafios de muitas organizações contemporâneas, uma vez que o desenvolvimento de capital intelectual qualificado normalmente exige tempo e recursos financeiros consideráveis (BONTIS, 2001), como, também, são os casos das tecnologias da informação e da comunicação utilizadas no suporte às etapas do processo de inteligência competitiva, uma vez que eles também demandam recursos financeiros substanciais e capacidades cognitivas diferenciadas dos seus usuários. (MILLER, 2002; LIEBOWITZ, 2006)

Por ser uma pesquisa de natureza teórica, muitos indícios encontrados poderão ser efetivamente investigados por futuras pesquisas empíricas, como por exemplo: (a) de que forma os esforços de IC ajudam os estrategistas na antecipação $e$ neutralização das ameaças ambientais, como, também, na descoberta de novas oportunidades de negócios? (b) Como comparar o nível de eficiência de IC entre as organizações que operam dentro de um mesmo mercado consumidor? (c) O capital intelectual e as tecnologias da informação e comunicação necessárias para a consecução dos processos de geração e disseminação dos produtos de inteligência são recursos difíceis de serem adquiridos ou desenvolvidos pelas organizações concorrentes? Por último (d) Quais fatores internos e externos são determinantes para que as organizações estruturem processos eficientes e eficazes de IC?

Em conclusão, conforme exposto anteriormente, a IC tem se tornado em um importante campo de pesquisa na atualidade e muitas questões ainda precisam ser exploradas de melhor forma pelos pesquisadores contemporâneos, especialmente no contexto das organizações brasileiras.

\section{REFERÊNCIAS}

AMIT, R.; SCHOEMAKER, P. J. Strategic assets and organizational rent. Strategic Management Journal, Chicago, v. 14, p. 33-46, 1993.
ANG, S. H. Competitive Intensity and Collaboration:

Impact on Firm Growth Across Technological

Environments. Strategic Management Journal,

Chicago, v. 29, p. 1.057-1.075, 2008.

ANSOFF, Igor. Corporate Strategy. McGraw Hill, New York, 1965.

\section{Implantando a Administração Estratégica.}

São Paulo: Atlas, 1993.

ANTIA, K. D; HERSFORD, J.W. A Process-Oriented

View of Competitive Intelligence and its Impact on

Organizational Performance. Journal of Competitive

Intelligence and Management, USA, v. 4, n. 1, 2007.

BAIN, J. S. Barriers to New Competition. Cambridge, MA: Harvard University Press, 1956.

BARBOSA, R. R. Uso de fontes de informação para inteligência competitiva: um estudo da influência do porte das empresas sobre o comportamento informacional.

Encontros Bibli, Florianópolis, (UFSC), v. e n. especiais, p. 91-102, 2006.

BARNEY, J. B. Strategic factor markets: expectations, luck, and business strategy. Management Science, Maryland (USA), v. 32, n. 10, p. 1.231-1.241, 1986.

. Firm resources and sustained competitive advantage. Journal of Management, USA, v. 17, p. 99-120, 1991.

. Looking inside for competitive advantage.

Academy of Management Executive, New York, v. 9, p. 49-61, 1995.

. Is the resource-based "view" a useful perspective for strategic management research? Yes. Academy of

Management Review, Indiana, v. 26, p. 41-56, 2001.

Gaining and Sustaining Competitive

Advantage. 2. ed. Upper Saddle River, NJ: Prentice Hall, 2002.

BARNEY, J. B.; HESTERLY, Willian S. Administração estratégica e vantagem competitiva. São Paulo:

Pearson Prentice Hall, 2007. 
BERGERON, P.; HILLER, C. A. Competitive intelligence. Annual Review of Information Science and Technology, USA, v. 36, p. 353-390, 2002.

\section{BERNHARDT, D. Competitive intelligence: how} to acquire and use corporate intelligence and counterintelligence. London: Prentice Hall, 2003.

BONTIS, N. Assessing knowledge assets: a review of the models used to measure intellectual capital. International Journal of Management Reviews, USA, v. 3, n. 1, p. 41-60, mar. 2001.

CHANDLER, A. Strategy and structure. Cambridge, MA: MIT Press, 1962.

CHEN, Ming-Jer. et al. Navigating in a hypercompetitive environment: the roles of action aggressiveness and TMT integration. Strategic Management Journal, Chicago, v. 31, p. $1.410-1.430,2010$.

\section{CHOO, C. W. Information management for the} intelligent organization. Medford, $\mathrm{NJ}$ : Information Today, 1995.

D’AVENI, R. A. Hipercompetição: estratégias para dominar a dinâmica de mercado. Rio de Janeiro: Campus, 1995.

D'AVENI, R. A. et al. The Age of Temporary Advantage. Strategic Management Journal, Chicago, v. 31, n. 13, p. 1.371-1.385, 2010.

DIERICKX, I.; COOL, K. Asset stock accumulation and sustainability of competitive advantage. Management Science, Maryland, v. 35, p. 1.504-1.511, 1989.

FULD, L. The new competitor intelligence. New York: Wiley, 1995.

GORDON, J. H. De olho na concorrência: como vencer a batalha por mercado e clientes. São Paulo: Futura, 2004.

GRANT, R. M. The resource-based theory of competitive advantage: implications for strategy formulation.

California Management Review, Spring, p. 114-135, 1991.
Prospering in dynamically-competitive environments: organizational capability as knowledge integration. Organizational Science, Califórnia, v. 7, n. 4, p. 375-397, 1996.

HAYEK, F. A. Economics and Knowledge. Economica, USA, v. 4, p. 33-54, 1937.

. The use of knowledge in society. American

Economic Review, Pittsburgh, v. 35, n. 4, p. 519-530, 1945.

HERRING, J. P. Tópicos fundamentais de inteligência: processo para identificação e definição de necessidades de inteligência. In: PRESCOTT, John E.; MILLER, Stephen $\mathrm{H}$. Inteligência competitiva na prática. São Paulo: Editora Campus, 2002. p. 274-291.

KAHANER, L. Competitive intelligence: how to gather, analyze, and use information to move your business to the top. Nova York: Touchstone Books, 1996.

LIEBOWITZ, Jay. Strategic intelligence: business intelligence, competitive intelligence, and knowledge management. [S.1.]: Auerbach, 2006.

MAGUIRE, S.; OJIAKO, U.; ROBSON, I. The intelligence alchemy and the twenty-first century organization.

Strategic Change, USA, v. 18, p. 125-139, 2009.

MAHONEY, J. T.; PANDIAN, J. R. The resource-based view within the conversation of strategic management.

Strategic Management Journal, Chicago, v. 13, n. 5, p. 363-380, June 1992.

MASON, E.S. Price and Production Policies of LargeScale Enterprise. American Economic Review, Pittsburgh, v. XXIX, p. 64-71. March, 1939.

McGONAGLE, J. J.; VELLA, C. M. Competitive intelligence in action. The Information Management Journal, Kansas, March-April, 2004.

MILLER, J. P. O milênio da Inteligência

Competitiva. Porto Alegre: Bookman, 2002.

NEWBERT, S. L. Empirical research on the resourcebased view of the firm: an assessment and suggestions for future research. Strategic Management Journal, Chicago, v. 28, n. 2, p. 121-146, 2007. 
NONAKA, Ikujiro; TAKEUCHI, Hirotaka. The knowledge-creating company: how Japanese companies create the dynamics of innovation. New York, NY: Oxford University Press, 1995.

MORESI, E. A. D. Inteligência organizacional: um referencial integrado. Ci. Inf., Brasília, v. 30, n. 2, p. 35 46, maio-ago. 2001.

OLIVEIRA, P. H. et al. Práticas de inteligência competitiva no setor varejista de Belo Horizonte: um estudo exploratório. In: $\mathbf{2 0}^{\circ}$ Congresso Internacional de Administração, 2007, Ponta Grossa: UEPG, 2007.

PETERAF, M. A. The cornerstones of competitive advantage: a resource-based view. Strategic Management Journal, Chicago, v. 14, p. 179-191, 1993.

PIRTTIMÄKI, Virpi. Comparative Study and Analysis of the Intelligence Activities of Large Finnish Companies.

Journal of Competitive Intelligence and Management, USA, v. 4, n. 1, 2007.

PORTER, M. E. Competitive strategy: techniques for analyzing industries and competitors. New York: Free Press, 1980.

The contributions of industrial organization to strategic management, Academy of Management Review, New York, v. 6, n. 4, p. 609-620, Apr. 1981.

Competitive advantage: creating and sustaining superior performance. New York: Free Press, 1985.

PRESCOTT, J. E. The evolution of competitive intelligence: design a process for action. Spring: APMP, 1999.

QIU, Tianjiao. Scanning for competitive intelligence: a managerial perspective. European Journal of Marketing, UK, v. 42, n. 7/8, p. 814-835, 2008.

SCHUMPETER, J. A. The theory of Economic Development. Cambridge: Harvard University Press, 1934.
SIRMON, D. G. et al. The dynamic interplay of capability strengths and weaknesses: investigating the bases of temporary competitive advantage. Strategic Management Journal, Chicago, v. 31, p. 1.386-1.409, 2010.

SPENDER, J. C. Making knowledge the basis of a dynamic theory of the firm. Strategic Management Journal, Chicago, v. 17, p. 45-62, 1996.

STAREC, C; GOMES, E. B. P; BEZERRA, J. (Org.). Gestão estratégica da informação e inteligência competitiva. São Paulo: Saraiva, 2005.

TARAPANOFF, Kira. Inteligência organizacional e competitiva. Brasília: Unb, 2001.

TYSON, K. W. M. The complete guide to competitive intelligence. Lisle (Chicago): Kirk Tyson International, 1998.

WERNERFELT, B. A resource-based view of the firm. Strategic Management Journal, Chicago, v. 5, p. 171$180,1984$.

WEST, C. Competitive intelligence. New York: Palgrave, 2001.

ZANGOUEINEZHAD, A.; MOSHABAKI, A. The role of structural capital on competitive intelligence. Industrial Management \& Data Systems, USA, v. 109, n. 2, p. 262- 280, 2009. 